\title{
Rapid identification of pork for halal authentication using the electronic nose and gas chromatography mass spectrometer with headspace analyzer.
}

\begin{abstract}
The volatile compounds of pork, other meats and meat products were studied using an electronic nose and gas chromatography mass spectrometer with headspace analyzer (GCMSHS) for halal verification. The $z$ Nose $^{\mathrm{TM}}$ was successfully employed for identification and differentiation of pork and pork sausages from beef, mutton and chicken meats and sausages which were achieved using a visual odor pattern called VaporPrint ${ }^{\mathrm{TM}}$, derived from the frequency of the surface acoustic wave (SAW) detector of the electronic nose. GCMS-HS was employed to separate and analyze the headspace gasses from samples into peaks corresponding to individual compounds for the purpose of identification. Principal component analysis (PCA) was applied for data interpretation. Analysis by PCA was able to cluster and discriminate pork from other types of meats and sausages. It was shown that PCA could provide a good separation of the samples with $67 \%$ of the total variance accounted by PC1.
\end{abstract}

Keyword: Authentication; Pork; Electronic nose; Surface 